\title{
Heteroepitaxial growth of III-V compound semiconductors for optoelectronic devices
}

\author{
T EGAWA*, H ISHIKAWA, T JIMBO ${ }^{\dagger}$ and M UMENO \\ Research Centre of Micro-Structure Devices, Nagoya Institute of Technology, Gokiso-cho, Showa-ku, \\ Nagoya 466-8555, Japan \\ 'Department of Environmental Technology and Urban Planning, Nagoya Institute of Technology, Gokiso-cho, \\ Showa-ku, Nagoya 466-8555, Japan
}

\begin{abstract}
An AlGaAs/GaAs multi-quantum well vertical-cavity surface-emitting laser diode (VCSELD) has been grown on a Si substrate using metalorganic chemical vapour deposition (MOCVD). The VCSELD with a 23-pair of AlAs/ $/ \mathrm{Al}_{0.1} \mathrm{Ga}_{0.9}$ As distributed Bragg reflector on a $\mathrm{Si}$ substrate exhibited a threshold current of $223 \mathrm{~mA}$ under continuous-wave condition at $220 \mathrm{~K}$. Electroluminescence observation showed that an optical degradation was caused by generation and growth of dark-line defects. An MOCVD-grown InGaN/AIGaN double-heterostructure light-emitting diode on a sapphire substrate exhibited an optical output power of $0.17 \mathrm{~mW}$, an external quantum efficiency of $0.2 \%$, a peak emission wavelength at $440 \mathrm{~nm}$ with a full width at half-maximum of $63 \mathrm{~nm}$ and a stable operation up to $3000 \mathrm{~h}$ under $30 \mathrm{~mA}$ DC operation at $30^{\circ} \mathrm{C}$. A high current level of $281 \mathrm{~mA} / \mathrm{mm}$ and a large transconductance $\left(g_{\mathrm{m}}\right)$ of $33 \mathrm{mS} / \mathrm{mm}$ have been achieved for a GaN metal semiconductor field-effect transistor (MESFET) with a gate length of $2 \mu \mathrm{m}$ and a width of $200 \mu \mathrm{m}$ at $25^{\circ} \mathrm{C}$. The GaN MESFET at $400^{\circ} \mathrm{C}$ showed degraded characteristics: a low $g_{\mathrm{m}}$ of $13.4 \mathrm{mS} / \mathrm{mm}$, a gate leakage and a poor pinch-off.
\end{abstract}

Keywords. GaAs/Si; GaN; MOCVD; MESFET; LED; vertical-cavity surface-emitting laser diode.

\section{Introduction}

Considerable scientific and engineering resources have been devoted to heteroepitaxial growth, such as GaAs on $\mathrm{Si}$ and $\mathrm{GaN}$ on sapphire. Vertical-cavity surfaceemitting laser diodes (VCSELDs) on $\mathrm{Si}$ are very attractive because of significant advantages over edge-emitting lateral-cavity laser diodes, such as the potential for wafer scale testing, high-density two-dimensional array fabrication, ultrafast parallel optical information processing and possibility of monolithic integration with other optical or electronic devices (Hayashi 1993). In particular, GaAs-based VCSELDs on Si are anticipated to be used in future optoelectronic integrated circuits (OEICs). However, previous investigations of laser diodes on $\mathrm{Si}$ substrates have focused on the conventional edge-emitting lateral-cavity structures. There have been only a few demonstrations of VCSELD on $\mathrm{Si}$ under the pulsed operation at $300 \mathrm{~K}$ by Deppe et al (1990) and Egawa et al (1994).

$\mathrm{GaN}$-based materials are candidates for high-density optical data storage, full-colour displays and electronic devices operating under high-power and high-temperature conditions due to large direct band gap, large saturation velocity, large breakdown electric field and chemical inertness. In the past few years, high-efficiency blue and

*Author for correspondence green light-emitting diodes (LEDs) (Nakamura et al 1994) and laser diodes operating under continuous-wave (CW) condition (Nakamura 1997) have been developed using GaN-based materials on sapphire substrates. There have been many researches on $\mathrm{GaN}$-based metal semiconductor field-effect transistors (MESFETs) (Khan et al 1993b; Binari et al 1994; Egawa et al 1998) and high electron mobility transistors (HEMTs) (Khan et al 1993a; Wu 1998).

One of the main problems encountered in the heteroepitaxial growth is that there are mismatches in the lattice constant and the thermal expansion coefficient between the epitaxial layer and the substrate. Two-step growth technique (Akiyama et al 1984) has been applied to the heteroepitaxial growth of $\mathrm{GaAs}$ on $\mathrm{Si}$ and $\mathrm{GaN}$ on sapphire. In these systems, however, the epitaxial layers contain high density of the threading dislocations and large strain due to the differences of lattice constants and thermal expansion coefficients between the epitaxial layers and the substrates (Egawa et al 1995a; Lester et al 1995). Dislocations acting as nonradiative recombination centres cause limitation of stable operation for optical devices under high injected current density and ambient temperature. For example, Egawa et al (1995a) have reported that rapid degradations in electrical and optical characteristics of $\mathrm{AlGaAs} / \mathrm{GaAs}$ single quantum well laser diodes on $\mathrm{Si}$ substrates were caused by formation of dark-line defects (DLDs) during high injected 
current density. In this study, we report the characteristics of the AlGaAs/GaAs VCSELD on $\mathrm{Si}$ substrate with 23-pair of $\mathrm{AlAs} / \mathrm{Al}_{0.1} \mathrm{Ga}_{0.9} \mathrm{As}$ distributed Bragg reflector (DBR), the InGaN/AlGaN LEDs on sapphire substrate and the GaN MESFET at high temperatures.

\section{Experimental}

\subsection{AlGaAs/GaAs VCSELD on Si}

An AlGaAs/GaAs VCSELD structure was grown on an $n^{+}$-Si substrate oriented $2^{\circ}$ off (100) toward [110] using metalorganic chemical vapour deposition (MOCVD) at atmospheric pressure (Egawa et al 1994). The VCSELD structure was grown on $\mathrm{Si}$ substrate at $750^{\circ} \mathrm{C}$ by the conventional two-step growth technique. The laser structure consists of a $2.1 \mu \mathrm{m}$ thick thermal-cycle annealed $n^{+}$-GaAs buffer layer, a 23-pair of $n^{+}$-AlAs $/ n^{+}-\mathrm{Al}_{0.1} \mathrm{Ga}_{0,9} \mathrm{As}$ $(71 \mathrm{~nm} / 60 \mathrm{~nm})$ quarter-wave multi-layer DBR, a $290 \mathrm{~nm}$ thick $n-\mathrm{Al}_{0.7} \mathrm{Ga}_{0.3}$ As lower cladding layer, a $51 \mathrm{~nm}$ thick undoped $\mathrm{Al}_{03} \mathrm{Ga}_{0,7} \mathrm{As}$ lower confining layer, ten undoped $9 \mathrm{~nm}$ thick GaAs multi-quantum well (MQW) active layers separated by $5.5 \mathrm{~nm}$ thick undoped $\mathrm{Al}_{0.3} \mathrm{Ga}_{0.7} \mathrm{As}$ barrier layers, a $51 \mathrm{~nm}$ thick undoped $\mathrm{Al}_{0: 3} \mathrm{Ga}_{0.7} \mathrm{As}$ upper confining layer, a $220 \mathrm{~nm}$ thick $p-\mathrm{Al}_{0,7} \mathrm{Ga}_{0,3} \mathrm{As}$ upper cladding layer, and a $34 \mathrm{~nm}$ thick $p^{+}-\mathrm{GaAs}$ contact layer. After the growth, the laser device was fabricated as follows: a $\mathrm{SiO}_{2}$ insulating layer was deposited on the $p^{+}$-GaAs contact layer and $50 \mu \mathrm{m}$ diameter contact windows were opened by wet chemical etching of $\mathrm{SiO}_{2}$. $\mathrm{Next}, \mathrm{Ti} / \mathrm{Au}$ were evaporated on the $p^{+}$-GaAs layer as a $p$-side electrode except for the $20 \mu \mathrm{m}$ diameter area at the centre of the $50 \mu \mathrm{m}$ diameter contact window. A semi-transparent $\mathrm{Au}$ was then evaporated on the $p$-side surface. AuSb/Au was used for the $n$-side electrode on the $n^{+}-\mathrm{Si}$ substrate. The devices were mounted (junction up) on sample holders and tested. In the VCSELD on $\mathrm{Si}$, the light output was measured by detecting the emitted light through the $20 \mu \mathrm{m}$ diameter semi-transparent $\mathrm{Au}$. The lifetime tests were examined under automatic power control (APC) condition. Growth of DLDs was studied using an electroluminescence (EL) observation system.

\subsection{InGaN/ALGaN LED and GaN MESFET on sapphire}

An InGaN/AlGaN LED was grown on the sapphire substrates with (0001) orientation (c face) by MOCVD at atmospheric pressure using the two-step growth technique (Egawa et al 1996). The structure consists of the following growth sequence: a $30 \mathrm{~nm}$ thick $\mathrm{GaN}$ nucleation layer, a $4 \mu \mathrm{m}$ thick $n$-GaN layer, a $150 \mathrm{~nm}$ thick $n$ $\mathrm{Al}_{0.15} \mathrm{Ga}_{0.85} \mathrm{~N}$ layer, a $50 \mathrm{~nm}$ thick $\mathrm{In}_{0.06} \mathrm{Ga}_{0.94} \mathrm{~N}$ layer, a $150 \mathrm{~nm}$ thick $p-\mathrm{Al}_{0.15} \mathrm{Ga}_{0.85} \mathrm{~N}$ layer, and a $350 \mathrm{~nm}$ thick $p$-type GaN cap layer. Thermal annealing in $\mathrm{N}_{2}$ ambient was performed to obtain $p$-type $\mathrm{GaN}$ and AlGaN layers at $750^{\circ} \mathrm{C}$ for $30 \mathrm{~min}$. After the growth, the sample was partially etched by reactive ion etching in a $\mathrm{BCl}_{3}$ plasma until the $n$-GaN layer was exposed. The ohmic electrodes of $\mathrm{Ni} / \mathrm{Au}$ and $\mathrm{Ti} / \mathrm{Al}$ were formed by vacuum evaporation on the $p$ - and $n$-GaN layers, respectively.

The GaN MESFET was grown on the sapphire substrate by MOCVD (Egawa et al 1998). The epitaxial layers consisted of a $30 \mathrm{~nm}$ thick $\mathrm{GaN}$ nucleation layer, a $2.4 \mu \mathrm{m}$ thick undoped $\mathrm{GaN}$ layer and a $0.2 \mu \mathrm{m}$ thick $n$-GaN layer with $\mathrm{Si}$ doped to $\sim 2 \times 10^{17} \mathrm{~cm}^{-3}$. After depositing $\mathrm{SiO}_{2}$ film on the $n$-type $\mathrm{GaN}$, the $22 \times 215 \mu \mathrm{m}$ mesas were defined on the $n$-GaN layer by use of standard photolithographic technique. These mesas were electrically isolated by reactive ion etching in a $\mathrm{BCl}_{3}$ plasma. The drain-source ohmic contacts were obtained with $\mathrm{Ti} / \mathrm{Al}$ annealed at $900^{\circ} \mathrm{C}$ for $60 \mathrm{sec}$ in $\mathrm{N}_{2}$ ambient. The gate metallization was done by vacuum evaporation of $\mathrm{Pt} / \mathrm{Ti} / \mathrm{Au}$. The gate length and width of the GaN MESFET were 2 and $200 \mu \mathrm{m}$, respectively, and the channel opening (source to drain distance) was $10 \mu \mathrm{m}$. The Hall effect measurements by van der Pauw method were performed for the $n$-GaN layer at various temperatures.

\section{Results and discussion}

\subsection{AlGaAs/GaAs VCSELD on Si}

Figure 1 shows the calculated and measured reflectivities of the 23-pair of $\mathrm{AlAs} / \mathrm{Al}_{0.1} \mathrm{Ga}_{0.9} \mathrm{As} \mathrm{DBR}$ on Si.

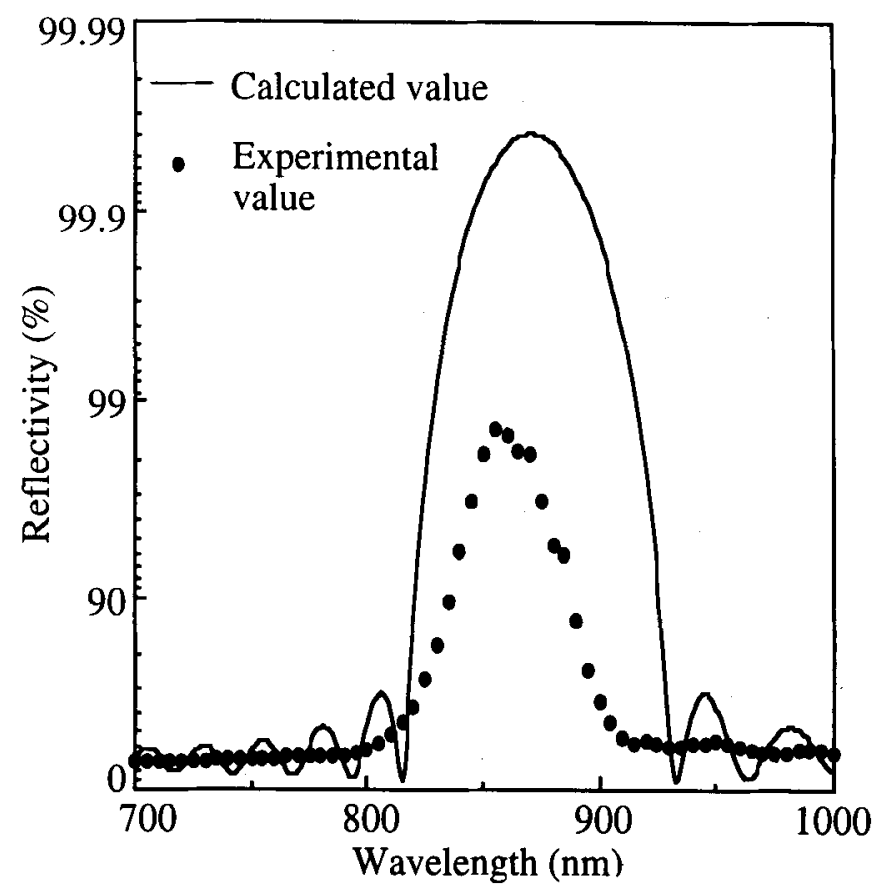

Figure 1. Calculated and measured reflectivities of the 23-pair of AlAs $/ \mathrm{Al}_{0.1} \mathrm{Ga}_{0.9} \mathrm{As} \mathrm{DBR}$ on $\mathrm{Si}$. 
The measured peak reflectivity of the 23-pair of AlAs $/ \mathrm{Al}_{0.1} \mathrm{Ga}_{0.9}$ As DBR on Si was $98.6 \%$ at $860 \mathrm{~nm}$. Comparing with the calculated reflectivity, the reflectivity of $98.6 \%$ still remains to be low probably due to the zigzag interfacial roughness and the $\mathrm{Al}-\mathrm{Ga}$ interdiffusion in the DBR on Si (Egawa et al 1995b). The top mirror had the reflectivity of $93.6 \%$ and transparency of $0.6 \%$ for the semi-transparent Au. Figure 2 shows $\mathrm{CW}$ lightcurrent $(L-I)$ characteristic and emission spectrum of the VCSELD at $100 \mathrm{~K}$. The VCSELD on Si exhibited the threshold current $\left(I_{\mathrm{th}}\right)$ of $73 \mathrm{~mA}$, the threshold current density $\left(J_{\mathrm{th}}\right)$ of $3.7 \mathrm{kA} / \mathrm{cm}^{2}$, and the external differential quantum efficiency $\left(\eta_{\mathrm{d}}\right)$ of $0.8 \%$. The VCSELD on Si showed the peak wavelength of $834.4 \mathrm{~nm}$ with the full width at half maximum (FWHM) of $39.5 \mathrm{~nm}$ at $0.96 \times I_{\text {th }}$, and $844 \mathrm{~nm}$ with the FWHM of $2.2 \mathrm{~nm}$ at $1.2 \times I_{\text {th }}$. The relatively broad FWHM of $2.2 \mathrm{~nm}$ may be due to the generation of multi transverse-modes near the single fundamental mode. We have achieved $\mathrm{CW}$ operation with the $I_{\text {th }}$ of $223 \mathrm{~mA}$ up to $220 \mathrm{~K}$ for the VCSELD on Si. The CW operation was thought to be achieved by the uses of the AlAs/AlGaAs DBR and MQW structure. Figure 3 shows the results from the aging tests for the VCSELD on Si operating at a constant output power under $300 \mathrm{~K}$ pulsed and $100 \mathrm{~K} \mathrm{CW}$ conditions. Under $300 \mathrm{~K}$ pulsed operation, the current increased gradually at a rate of $\sim 30 \mathrm{~mA} / \mathrm{h}$ in the first $170 \mathrm{~min}$ and then increased rapidly at $\sim 114 \mathrm{~mA} / \mathrm{h}$ in the next $90 \mathrm{~min}$. The VCSELD on Si degraded rapidly in $\sim 1$ min under the $\mathrm{CW}$ operation at $100 \mathrm{~K}$. The formation

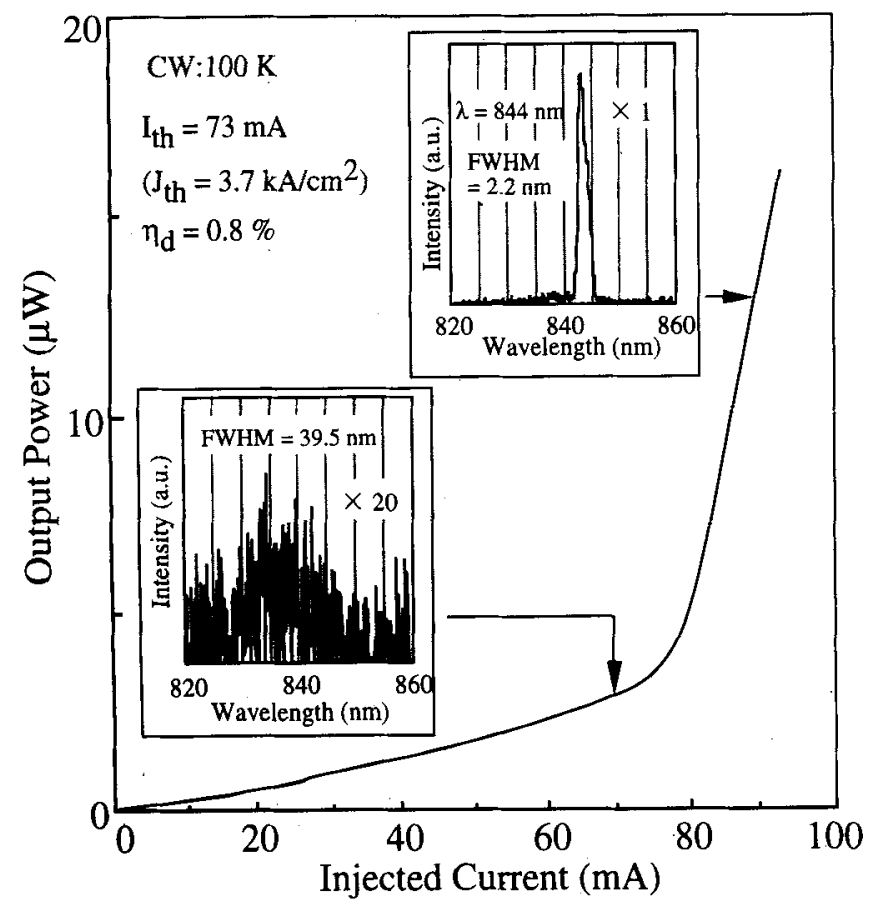

Figure 2. $L-I$ characteristic and emission spectrum under $C W$ condition at $100 \mathrm{~K}$ for the AlGaAs/GaAs VCSELD on Si. of DLDs was investigated for the VCSELD on Si using the EL observation to study the progressive optical degradation. The EL observations showed that the dark regions enlarged and resulted in the DLDs with the aging. Egawa et al (1995a) have reported that the growth of dark regions strongly depended on the injected current density. Therefore, the stable $\mathrm{CW}$ lasing operation was prevented by the rapid formation and propagation of the dark regions because the dark regions acted as the nonradiative recombination centres.

\subsection{InGaN/AlGaN LED and GaN MESFET on sapphire}

The InGaN/AlGaN LED exhibited a forward turn-on voltage of $3 \mathrm{~V}$ at the forward current of $1 \mathrm{~mA}$, and a reverse voltage of $10 \mathrm{~V}$ at a reverse current of $0.1 \mathrm{~mA}$. Figure 4 shows the $L-I$ characteristic of the InGaN/AlGaN LED on the sapphire substrate under DC operation at $30^{\circ} \mathrm{C}$. The InGaN/AIGaN LED exhibited the optical output power of $0.17 \mathrm{~mW}, \eta_{\mathrm{d}}$ of $0.2 \%$, and a peak emission spectrum at about $440 \mathrm{~nm}$ with FWHM of $63 \mathrm{~nm}$ at the injected current density of $60 \mathrm{~A} / \mathrm{cm}^{2}(30 \mathrm{~mA})$. The light output power increased linearly with increasing current, and saturated at a high injected current level probably due to heating. The inset of figure 4 shows an aging result of the LED under a constant current density of $60 \mathrm{~A} / \mathrm{cm}^{2}(30 \mathrm{~mA})$ at $30^{\circ} \mathrm{C}$. We confirmed the stable operation up to $3000 \mathrm{~h}$ under this aging condition.

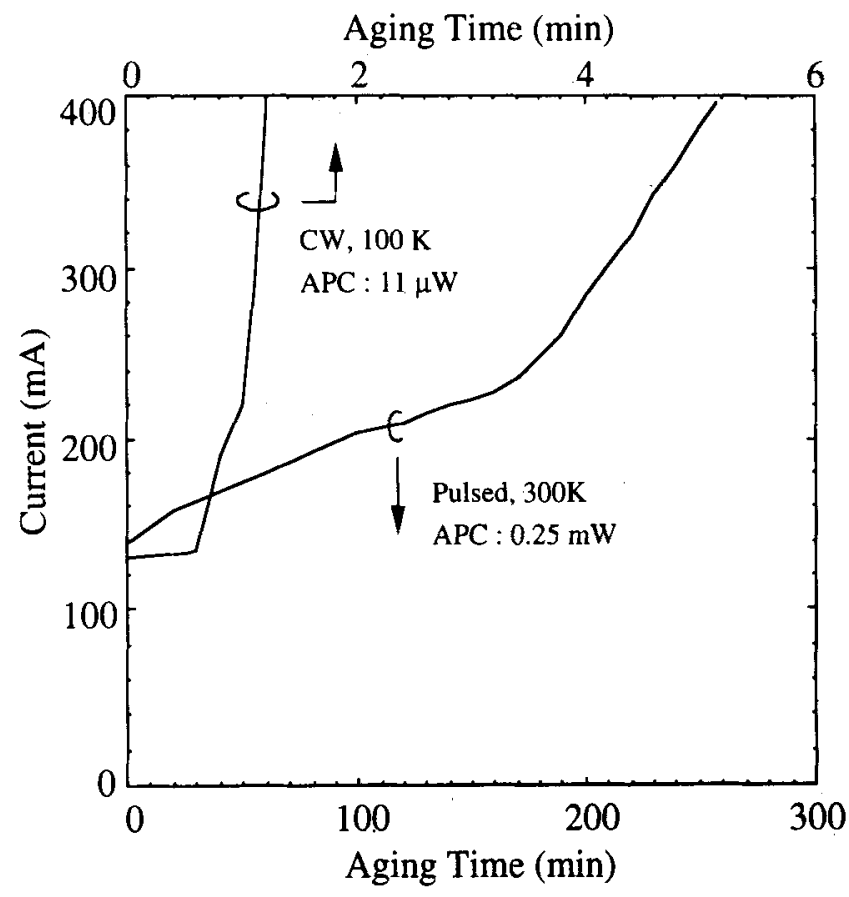

Figure 3. Results from the aging tests for the $A l G a A s / G a A s$ VCSELD on Si operating at a constant output power under $300 \mathrm{~K}$ pulsed and $100 \mathrm{~K} \mathrm{CW}$ conditions. 
The dependence of the Hall mobility for the Sidoped $n$-GaN layer on temperature is shown in figure 5 . The Hall mobility first increased by $T^{3 / 2}$ and then decreased by $T^{-3 / 2}$ with increasing temperature. The main scattering mechanisms which contributed to the Hall mobility appeared to be the ionized impurity scattering below $130 \mathrm{~K}$ and the acoustic phonon scattering above $130 \mathrm{~K}$. The Hall mobilities of the $n$-GaN layer were $585 \mathrm{~cm}^{2} / \mathrm{V} \cdot \mathrm{s}$ with the electron carrier concentration of $1.1 \times 10^{17} \mathrm{~cm}^{-3}$ at $300 \mathrm{~K}$, and $1217 \mathrm{~cm}^{2} / \mathrm{V}$.s with that of $2.4 \times 10^{16} \mathrm{~cm}^{-3}$ at $77 \mathrm{~K}$. The maximum Hall mobility was $1476 \mathrm{~cm}^{2} / \mathrm{V} \cdot \mathrm{s}$ with the electron carrier concentration of $5.4 \times 10^{16} \mathrm{~cm}^{-3}$ at $130 \mathrm{~K}$. The Hall mobility obtained in this sample was much higher than the previous results by Khan et al (1993b) and Binari et al (1994).

Figure 6 shows the drain-source current $\left(I_{\mathrm{DS}}\right)$ characteristic as a function of the drain-source voltage $\left(V_{\mathrm{DS}}\right)$ for the gate bias $\left(V_{\mathrm{g}}\right)$ ranging from +1 to $-11 \mathrm{~V}$ at $25^{\circ} \mathrm{C}$. The GaN MESFET with the gate length of $2 \mu \mathrm{m}$ and the gate width of $200 \mu \mathrm{m}$ showed the maximum transconductance $\left(g_{\operatorname{mmax}}\right)$ of $33 \mathrm{mS} / \mathrm{mm}$, which was higher than the previously reported MESFETs by Khan et al (1993b) and Binari et al (1994). The value of $I_{\mathrm{DS}}$ was as high as $281 \mathrm{~mA} / \mathrm{mm}$ at $V_{\mathrm{g}}=1 \mathrm{~V}$ and $V_{\mathrm{DS}}=40 \mathrm{~V}$. The GaN MESFET exhibited the modulation characteristic with nearly pinch-off at the $V_{\text {th }}$ of approximately $-13 \mathrm{~V}$, which resulted from a sharp interface between the $n$-GaN and the undoped $\mathrm{GaN}$ layers. The temperature dependence of $g_{\mathrm{m}}$ for the GaN MESFET is shown in figure 7. With increasing temperature, the value of $g_{\mathrm{m}}$ decreased from

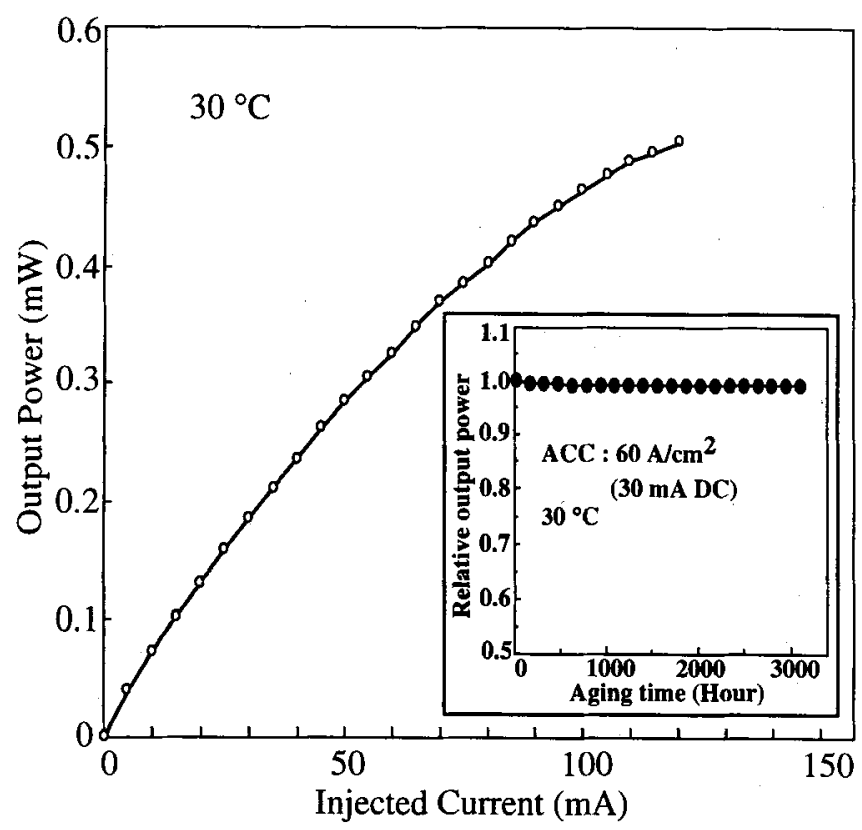

Figure 4. $L-I$ characteristic of the InGaN/AIGaN LED on sapphire under DC operation at $30^{\circ} \mathrm{C}$. The inset shows the aging result under a constant current density of $60 \mathrm{~A} / \mathrm{cm}^{2}$ $(30 \mathrm{~mA})$ at $30^{\circ} \mathrm{C}$.
$29.8 \mathrm{mS} / \mathrm{mm}$ at $25^{\circ} \mathrm{C}$ to $13.4 \mathrm{mS} / \mathrm{mm}$ at $400^{\circ} \mathrm{C}$. The $\mathrm{GaN}$ MESFET at $400^{\circ} \mathrm{C}$ exhibited the gate leakage, the poor pinch-off and the low $g_{\mathrm{m}}$ in comparison to that of the MESFET measured at $25^{\circ} \mathrm{C}$. As expected from figure 5, the decreases in $g_{\mathrm{m}}$ were caused by the reduction of the electron mobility at high temperature. The data shown by open circle in figure 7 indicates the $g_{\mathrm{m}}$ at $25^{\circ} \mathrm{C}$

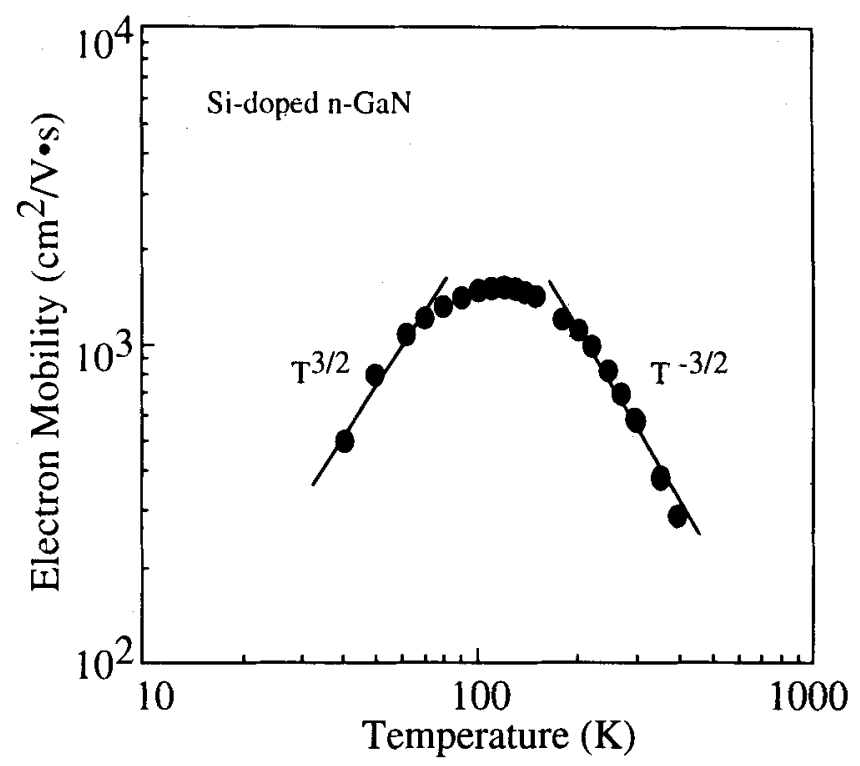

Figure 5. Temperature dependence of electron mobility for the $n$-GaN layer grown on sapphire by MOCVD.

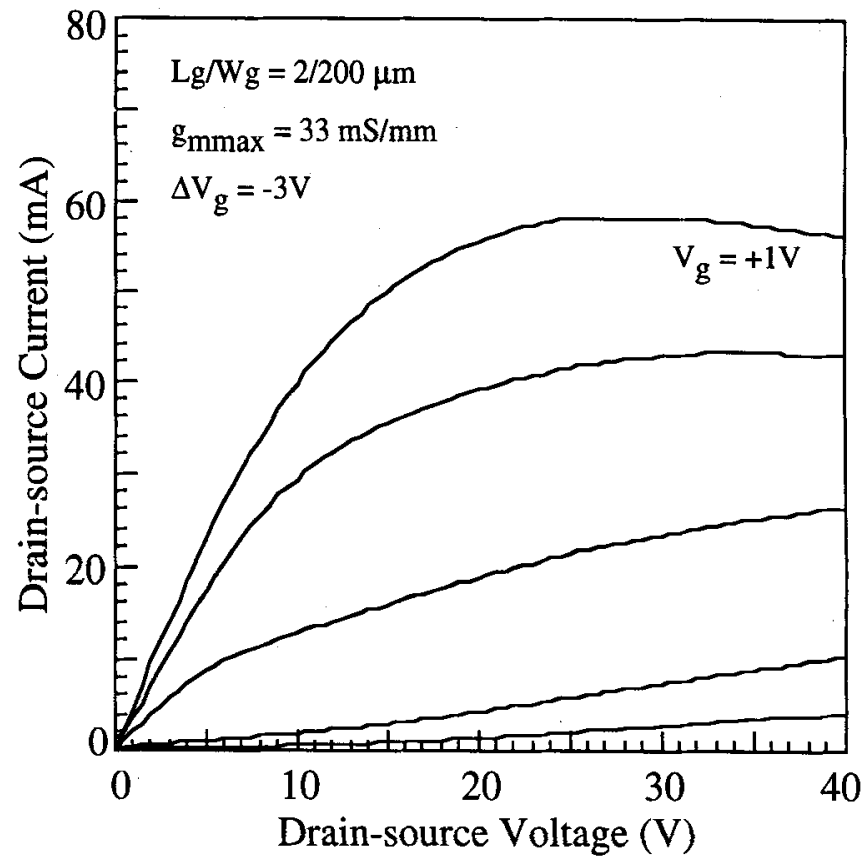

Figure 6. Drain-source current $\left(I_{\mathrm{DS}}\right)$ characteristic of the GaN MESFET at $25^{\circ} \mathrm{C}$ as a function of the drain-source voltage $\left(V_{\mathrm{DS}}\right)$. The gate length and width are 2 and $200 \mu \mathrm{m}$, respectively. 


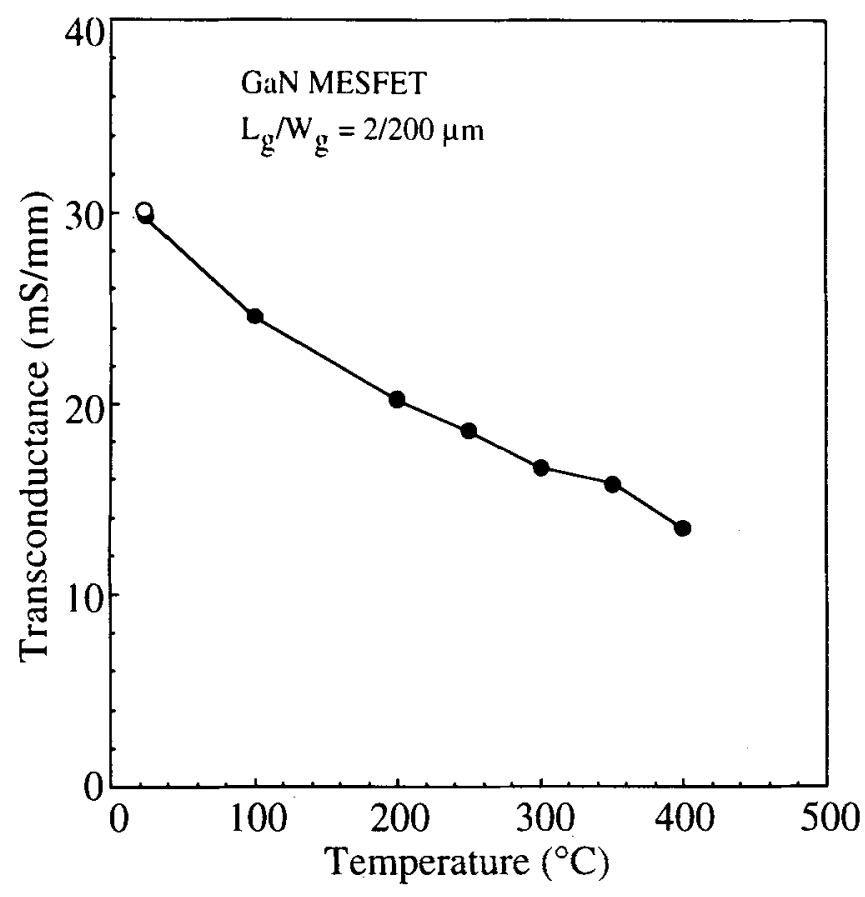

Figure 7. Temperature dependence of transconductance $\left(g_{\mathrm{m}}\right)$ for the GaN MESFET. Open circle shows the value at $25^{\circ} \mathrm{C}$ measured again after its measurement at $400^{\circ} \mathrm{C}$.

measured again after its measurement at $400^{\circ} \mathrm{C}$. Although a little gate leak was observed, the GaN MESFET showed the initial characteristic with the $g_{\mathrm{m}}$ of $30 \mathrm{mS} / \mathrm{mm}$. This gate leak at $25^{\circ} \mathrm{C}$ was caused by the degradation of Schottky gate metal after the measurements at high temperatures.

\section{Conclusions}

The CW operation up to $220 \mathrm{~K}$ has been demonstrated for the AlGaAs/GaAs MQW VCSELD on $\mathrm{Si}$ with the 23-pair of AlAs/Al ${ }_{0.1} \mathrm{Ga}_{0.9} \mathrm{As}$ DBR. The value of $I_{\text {th }}$ under the CW operation was $223 \mathrm{~mA}$ at $220 \mathrm{~K}$. However, the VCSELD on Si showed the optical degradation due to the generation and growth of DLDs. The InGaN/AIGaN LED on sapphire grown by MOCVD exhibited the optical output power of $0.17 \mathrm{~mW}$, the external quantum efficiency of $0.2 \%$, the peak emitting spectrum at $440 \mathrm{~nm}$ with FWHM of $63 \mathrm{~nm}$ and the stable operation up to $3000 \mathrm{~h}$ under $30 \mathrm{~mA} \mathrm{DC}$ operation at $30^{\circ} \mathrm{C}$. The MOCVD-grown GaN MESFET with the gate length of $2 \mu \mathrm{m}$ and the width of $200 \mu \mathrm{m}$ showed the high current level of $281 \mathrm{~mA} / \mathrm{mm}$ and the large $g_{\mathrm{m}}$ of $33 \mathrm{mS} / \mathrm{mm}$ at $25^{\circ} \mathrm{C}$, which resulted from the electron mobility as high as $585 \mathrm{~cm}^{2} / \mathrm{V} \cdot \mathrm{s}$ at $300 \mathrm{~K}$. Although DC characteristics were degraded at high temperature, the GaN MESFET exhibited the $g_{\mathrm{m}}$ of $13.4 \mathrm{mS} / \mathrm{mm}$ at $400^{\circ} \mathrm{C}$.

\section{Acknowledgements}

This work was partially supported by a Grant-in-Aid for Scientific Research (c) (09650049) by the Ministry of Education, Science, Sports and Culture, Japan.

\section{References}

Akiyama M, Kawarada Y and Kaminishi K 1984 Jpn J. Appl. Phys. 23 L843

Binari S C, Rowland L B, Kruppa W, Kelmer G, Doverspike K and Gaskill D K 1994 Electron. Lett. 301248

Deppe D G, Chand N, van der Ziel J P and Zydzik G J 1990 Appl. Phys. Lett. 56740

Egawa T, Hasegawa Y, Jimbo T and Umeno M 1994 IEEE Photon. Technol. Lett. 6681

Egawa T, Hasegawa Y, Jimbo T and Umeno M 1995a Appl. Phys. Lett. 672995

Egawa T, Jimbo T and Umeno M 1995b J. Appl. Phys. Lett. 773836

Egawa T, Ishikawa H, Jimbo T and Umeno M 1996 Appl. Phys. Lett. 69830

Egawa T, Ishikawa H, Jimbo T and Umeno M 1998 Electron. Lett. 34598

Hayashi I 1993 Jpn J. Appl. Phys. 32266

Khan M A, Bhattarai A, Kuznia J N and Olson D T 1993a Appl. Phys. Lett. 631214

Khan M A, Kuznia J N, Bhattarai A R and Olson D T 1993b Appl. Phys. Lett. 621786

Lester S D, Ponce F A, Craford M G and Steigerwald D A 1995 Appl. Phys. Lett. 661249

Nakamura S 1997 Mater. Res. Soc. Symp. Proc. 4491135

Nakamura S, Mukai T and Senoh M 1994 Appl. Phys. Lett. 64 1687

Wu Y-F, Keller B P, Fini P, Keller S, Jenkins T J, Kehias L T, Denbaars S P and Mishra U K 1998 IEEE Electron Device Lett. 1950 